\title{
The Application of Big Data Technology in the Practical Research Work of Ideological and Political Courses
}

\author{
Yuhong Bai ${ }^{1}$ \\ ${ }^{1}$ Hulunbuir University, Hulunbuir 021008, Inner Mongolia
}

\begin{abstract}
This article analyzes the application advantages, application core and technical nature of big data technology. The author studies the specific application of big data technology in the allocation of topics, preclass research, data collection and processing, data statistical analysis, and data rational application. This article studies how to do well in survey method training, how to improve the data management system, how to strengthen the curriculum construction of colleges and universities, and how to actively learn from successful cases. The author's purpose is to enhance the application value of big data technology and improve the reliability of the practical survey results of ideological and political courses.
\end{abstract}

\section{Introduction}

With the continuous improvement of the quality of social life, people's requirements for the quality of social research are also increasing. If traditional research methods are still used for data collection, the integrity of the data information obtained will also be greatly affected. Big data technology has good promotion value in the practical research work of ideological and political courses because of its advantages of fast data collection and high accuracy. The application of big data technology to the practical research work of ideological and political courses can not only improve the integrity of the data collation results, but also has a positive significance for improving the scientificity of the research results.

\section{Big Data Technology Related Content Analysis}

\subsection{Application Advantage}

Big data has the characteristics of large volume, fast speed, diversification and high value. Firstly, large volume is the most significant feature that distinguishes big data from traditional data. According to statistics and calculations, by 2022 , the global data will reach $40 \mathrm{ZB}(1 \mathrm{ZB}=1$ trillion GB). Such a huge data resource will become the most solid foundation for big data technology to play a role. Secondly, fast speed refers to the fast frequency of data generation, replacement, and transmission. In the information age, the amount of data is continuously increasing at a rate of $1 \%$ $10 \%$, and the frequency of data update is also controlled at the ns level, and the total amount of data is very rich. Thirdly, diversification means that the sources and types of data are very rich, and they are constantly increasing.
From the number of rail transit operations to the mileage of passenger planes, from doctors' prescriptions to patients' medicines, the types of data are all-encompassing and will continue to increase over time. Fourth, high value means that big data technology can play a greater role than the original data after integrating and utilizing massive amounts of data. Although the value density of a single data is low, the relationship between the data can be found through the processing of scientific systems and algorithms, which breaks through the value limitations of the original data.

\subsection{Application Core}

The key to the realization of the value of massive data lies in its forecasting function. Through the sorting and summarization of data, the mastery of dynamic laws can realize the formal forecast of a certain stage in the future. For example, the famous American Netflix film and television company judges the British original "House of Cards" and the United States based on the user's viewing habits such as which node to pause at, which node to fast forward, or which actor searched for after a certain film, etc. The famous actor Kevin Spacey was the hot spot pursued by the market at that time. That's why the hit American drama "House of Cards" succeeded. The massive amount of user data that Netflix had at the time was a very valuable resource. Each individual user data may be meaningless, but when thousands of users are searching for a certain actor's work, it can explain the problem. In the context of the big data era, the convenience of data acquisition is also improving. The most critical content is how to use big data rationally and sort out the correlation between data. In this way, the data can be optimized and sorted, and the regularity between the data can be found to meet the data forecasting requirements. 


\subsection{Technical Essence}

Analyzing the essence of technology, the essence of big data technology is "hidden communication." More than $95 \%$ of the information sources of big data are the products of social life and activities, but the ultimate purpose of the services generated is to provide people with high-quality services. This also means that big data is essentially the information communication between people in the application, and this type of communication is not direct information exchange in the application. It is a kind of "hidden communication" based on the data information mastered under the background of complex data application. Moreover, people's communication with each other has also changed with the change of the times, and there have been changes at different levels. In the initial period, more than $60 \%$ of communication was accomplished through physical movements. In the followup, when the initial language appeared, many words were not used as an aid. For example, many ethnic minorities in modern China rely on oral transmission to pass on their culture. Later, when writing and language were formed, relying on the Internet and telephone, people's communication methods also showed rich characteristics. Big data, as a necessary product during the current stage of social development, not only provides a more convenient way of communication, but also satisfies people's basic requirements for information content.

\section{The Application of Big Data Technology in the Practical Research work of Ideological and Political Courses}

\subsection{Assign Topic}

In order to successfully complete the practical research work of ideological and political courses, the first task in practical application is to complete the related work of assigning topics and clarify the specific rules of the work. In the specific practice process, teachers can use the sorting function of big data technology to filter out topics that meet the needs of students according to the professional characteristics of students. For example, for students majoring in computer science, teachers can assign topics such as "Network Changes Life" and "Science and Technology Development Value". In this way, while satisfying the purpose of ideological and political teaching, it can also improve the professional ability of personnel. For students majoring in agriculture, teachers can assign topics such as "ecological planting development" and "biological control". Based on big data technology, teachers can initially grade the difficulty of the selected topic, and provide the topic selection in the order from simple to difficult, and gradually cultivate the practical research ability of college students. For each topic, the teacher will arrange 1-2 groups of people to complete it. The group members will be limited to 3-5 according to the difficulty of the topic, so as to avoid too many members who are not actively participating. In addition, according to statistics in 2020 , more than $95 \%$ of students will use WeChat as their main social tool, and almost everyone has QQ. Therefore, teachers can use WeChat or QQ to form groups for problem communication and problem solving, which can ensure that problems can be solved smoothly.

\subsection{Pre-class Research}

After completing the topic selection, enter the pre-class research stage. That is to analyze the content of the preclass research and sort out the detailed content of the research work, so as to improve the orderliness of the research process. Based on big data technology, it can provide necessary reference for the advancement of preclass research work. Teachers can organize students to conduct group training after organizing the content of important test sites. Moreover, teachers will also conduct group tutoring to ensure the smooth progress of practical activities. In the specific evaluation process, the content flow is as follows. First, use some actual cases to express the value of social research content to students, and analyze the commonly used research methods. This allows students to choose the most appropriate homework method based on the actual situation. Second, introduce the format and content of the research report to the students to develop the application design. This can also further improve the reliability of the analysis results. Third, select $30 \%-40 \%$ of the excellent works from the previous works for display, to provide students with some new ideas. In addition, teachers also need to analyze various theories including Marxism, Engelsism, Leninism and so on. Teachers can use this to complete the analysis of real problems, leaving enough time for the group to discuss, so as to meet the group's independent research task.

\subsection{Data Collection and Processing}

During the traditional investigation method, the total amount of data collected in order to improve the reliability of the evaluation results is relatively high. In the process of applying big data technology, the ability to obtain valuable data is relatively strong. Especially in the process of sorting non-relational database data, relevant staff can use the data platform established by big data technology to conduct detailed analysis on the data types. Under normal circumstances, ETL tools are used to complete the distribution and sorting of content in the process of data information collection, and it also has a good application in the processing of heterogeneous data, plane control data, and related data. All collected data information will be directly put into the middle layer for cleaning, conversion, integration and other processing, and will also be directly loaded into the data warehouse after finishing the data. In this way, the analysis and processing of data information can be completed online smoothly, and the basic value of the data information mined can be improved. Compared with the previous data collation model, the shared platform established by big data technology can also use redundant design mechanisms and cloud computing mechanisms. In this way, information can be sorted out in 
an ultra-short time and the use value of data analysis results can be improved [1].

\subsection{Statistical Analysis of Data}

\subsubsection{Regression Model Variable Selection}

In the variable selection of the regression model, teachers need to determine the corresponding content of different indicators. Under normal circumstances, teachers will use students' research ability as the dependent variable in the entire regression model, denoted as y. This indicator can be divided into two groups of applied indicators, which are scoring for teachers (denoted as y1) and students' selfevaluation (denoted as y2). Take a case as an example, as shown in Figure 1. The abscissa represents the interval between the fights, and the ordinate is the effective number of people who have obtained the score. After calculating according to the content of Figure 1, it can be concluded that $15.31 \%$ of the students in the class get a "pass (60-69 points)" score. The number of people who got "good (70-84 points)" scores accounted for 53.31\%, and the number of people who got "excellent (85-8100 points)" scores accounted for $32.41 \%$. The content of the students' self-evaluation is based on the ability improvement evaluation form. The quantitative indicators generally need to be considered include classroom learning effect (denoted as a1), students' understanding of the textbook after reporting (denoted as a2), practical link impact (denoted as a3), and practical result impact (denoted as a4). From this, two sets of variable calculation formulas can be obtained, which are divided into $\mathrm{y}=\mathrm{y} 1+\mathrm{ky} 2(\mathrm{k}$ is a constant value) and $\mathrm{y} 2=\mathrm{a} 1+\mathrm{a} 2+\mathrm{a} 3+\mathrm{a} 4[2]$.

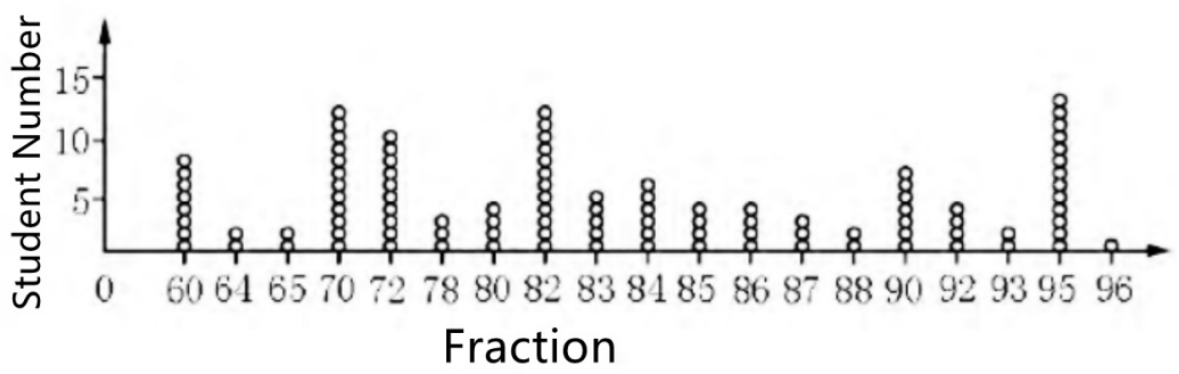

Fig.1 Teacher Evaluation Score Distribution

\subsubsection{Linear Regression Model Design}

Teachers need to design the corresponding management formula in advance when designing the linear regression model. The specific formula is as follows: $\mathrm{y}=\mathrm{b} 1 \mathrm{x} 1+\mathrm{b} 2 \times 2+\mathrm{b} 3 \times 3+\mathrm{b} 4 \times 4+a$. Among them, b1-b4 are commonly used coefficients, $\mathrm{x} 1-\mathrm{x} 4$ represent independent variables, and a represents the error correction term after calculation. Enter the prepared variable information into the SPSS software for analysis, and obtain the required linear regression equation. This process also requires big data technology to be able to continuously provide calculated data, and at the same time to analyze the value of the dependent variable to prove the application value of the collected data variable. In the process of data analysis and application, statistics related knowledge is also involved. Teachers can use the calculation of $P$ value to discuss the correlation between different variables. This is also the basic requirement for improving students' comprehensive ability [3].

\subsection{Reasonable Application of Data}

Based on the application advantages of big data technology, when dealing with problems, it can have a greater impact on the knowledge framework, thinking logic, and behavior content of the course content. Big data can enrich network data sources, microblog processing information, WeChat official accounts, video images, and photo information. The processing capabilities of big data technology can accurately process this information, and in the process, big data can also quickly filter out value data. This is also an important measure to enhance the attractiveness of research content. For example, in the "Fudan University Poisoning Case", a Baidu account began to conduct "science popularization" on the effects of some drugs and how to use daily necessities to configure poisons. This has also brought a very bad influence, and it is also an intuitive manifestation of personality distortion. This also requires that the practical research work of ideological and political courses will also be fully applied to Internet information resources in the development process, extract key information from the information, and spread positive energy topics. This also provides reliable conditions for the smooth reform of theoretical and practical courses [4].

\section{Suggestions on Optimizing the Practical Investigation of Ideological and Political Course}

\subsection{Do A Good Job in Survey Method Training}

Training on investigation methods is conducive to the smooth development of investigation work, thereby improving the reliability of investigation results. When students use big data technology to carry out practical research work, the primary task is to use appropriate survey methods to complete social practical activities, so as to improve the rationality of the research activities. For example, a university conducted group training for students before the start of work. Moreover, the school 
also printed the "Social Research Work Guide" in the curriculum to assist students in learning related content. The teacher will organize the group leader to conduct a second training after the student group training, so that they can systematically recognize the work content and help the group better complete the research task. In addition, the school uses the overall planning function of big data technology to make overall arrangements for the work content. This not only improves the use value of the research results, meets the corresponding management needs, but also improves the practicability and reliability of the management results [5].

\subsection{Improve the Data Management System}

By improving the data management system, the guiding value of the system content itself can be improved, and the rationality of extracting data content can be improved. The primary task of improving the reliability of course research results is to organize big data information with the help of a complete data management system, so as to give full play to the application value of the data itself. Moreover, the formulation of the system can also ensure the authenticity and rationality of the collected data, prevent others from maliciously modifying the data, and improve the application efficiency of the secondary use of data. At present, Internet technology has provided a lot of convenience to people's lives, and at the same time, it has also caused some undesirable problems such as privacy leakage and information theft. Ideological and political education is a course that correctly guides the development of personal thoughts. Its primary task when using big data technology to collect social survey data is to strictly abide by the content of the system and ensure the rationality of data sources. In this way, the data information can be sorted out better, and the timeliness of the data application results can be improved [6].

\subsection{Strengthen the Construction of College Courses}

By strengthening the curriculum construction of colleges and universities, the pertinence of the practical research work can be improved, and the use value of the curriculum content itself can be improved. In the specific practice process, we need to focus on the optimal design of the theoretical course content, so as to enhance ideology and meet the needs of the smooth development of follow-up research work. The ideological and political theory courses based on the application advantages provided by big data technology need to fit the current social development trends and trends. We need to incorporate digital content into the curriculum design, and at the same time we need to optimize the teaching methods. For example, micro-classes and short videos are used to implement theoretical knowledge into practical activities. In this way, the students' attention can be better attracted during the teaching process, and the students' knowledge learning ability can be gradually improved. Otherwise, schools can use the assessment system established by big data technology to adjust the teaching progress of college courses based on the assessment results. This not only enables it to have sufficient theoretical knowledge, but also enables it to be better applied in practice to meet the application requirements of college courses [7].

\subsection{Actively Learn from Successful Cases}

By actively learning from successful cases, it can provide guidance for students to carry out research work and reduce the appearance of unreasonable problems. At present, many universities have used big data technology to assist the research work of ideological and political courses. Moreover, there are also many successful cases uploaded in the Internet field. At this point, we can use big data technology to organize such content. Teachers will also conduct a detailed analysis of the content of these cases when intensively training students, and pick out the shortcomings and strengths of such cases. Besides, teachers will also simulate the research environment to allow students to draw up research plans and exercise their comprehensive abilities through virtual practice. This can not only lay the foundation for the smooth development of follow-up work, but also ensure the orderly and practicality of the process of carrying out such activities [8].

\section{Conclusion}

In summary, good investigation method training is conducive to the smooth development of investigation work. Improving the data management system can enhance the guiding value of the system content itself. Strengthening the curriculum construction of colleges and universities can improve the pertinence of the process of practical research work. Actively learning from successful cases can provide guidance for students to carry out research work. The application of big data technology to the research work of ideological and political courses has positive significance for accelerating the speed of research work.

\section{Acknowledgments}

Fund project: The 2020 Hulunbuir College Scientific Research Project "Research on the Cultivation Mechanism of University Network Cultural Works in Major Epidemic Prevention and Control-Taking Hulunbuir College as an Example", Item Number: 2020SZC10

\section{References}

1. Wei Chonghui, $\mathrm{Xu}$ Mengping. Evaluation of Ideological and Political Course Teachers in Colleges and Universities: Theoretical Basis, Realistic Dilemma and Construction Path [J]. Heilongjiang Higher Education Research, 2021, 39(04): 113-116.

2. Liu Chunqing. The practice of ideological and political reform in colleges and universities in the new era of heritage resource innovation $[\mathrm{J}]$. Cultural Industry, 2021(09): 126-127. 
3. Cai Xiaokui, Chu Shuijiang. Research on the current situation of the unification of theory and practice of ideological and political courses[J]. Journal of Guangdong Institute of Light Industry and Technology, 2021, 20(01): 69-73+80.

4. Gou Rong, Liu Wei, Li Chen. The construction and implementation of practical courses in ideological and political theory courses in colleges and universities[J]. Journal of Taiyuan Urban Vocational and Technical College, 2021(03): 122-124.

5. Shen Feiwei, Chen Xiaoling. Practical logic and optimization strategies for improving the teaching quality of ideological and political courses in colleges and universities on the platform of "learning to strengthen the country" $[J]$. Shenzhen Social Sciences, 2021, 4(02): 147-158.

6. Zhang Nan. Exploration of the Informationization of Ideological and Political Education in Colleges and Universities in the Era of Big Data-Comment on "Theory and Practice of Flipped Classroom in Ideological and Political Courses in Colleges and Universities in the Internet Era" $[\mathrm{J}]$. Science and Technology Management Research, 2021, 41(03):218.

7. Huang Weihong. Exploring the innovation of the fiveyear higher vocational ideological and political course teaching in the era of big data[J]. Journal of Jiamusi Vocational College, 2021, 37(01): 111-113.

8. Zhang Haidong, Li Qianghua. Research on the construction of a sharing platform for practical teaching resources of ideological and political courses in colleges and universities[J]. Journal of Luliang University, 2020, 10(06): 60-62. 